\title{
Multilayer Electrolyzer Stack Converts Carbon Dioxide to Gas Products at High Pressure with High Efficiency
}

\author{
B. Endrődi, ${ }^{\dagger} \dagger$ E. Kecsenovity, ${ }^{\dagger}$ A. Samu, ${ }^{\dagger}$ F. Darvas, ${ }^{\dagger}$ R. V. Jones, ${ }^{\ddagger}$ V. Török, ${ }^{\ddagger}$ A. Danyi, ${ }^{\dagger}$
} and C. Janáky* ${ }^{* \dagger \odot}$

${ }^{\dagger}$ Department of Physical Chemistry and Materials Science, Interdisciplinary Excellence Centre, University of Szeged, Rerrich Square 1, Szeged H-6720, Hungary

†ThalesNano Inc., Záhony u. 7, Budapest 1031, Hungary

Supporting Information

ABSTRACT: Electrochemical reduction of $\mathrm{CO}_{2}$ is a value-added approach to both decrease the atmospheric emission of carbon dioxide and form valuable chemicals. We present a zero gap electrolyzer cell, which continuously converts gas phase $\mathrm{CO}_{2}$ to products without using any liquid catholyte. This is the first report of a multilayer $\mathrm{CO}_{2}$ electrolyzer stack for scaling up the electrolysis process. $\mathrm{CO}$ formation with partial current densities above $250 \mathrm{~mA}$ $\mathrm{cm}^{-2}$ were achieved routinely, which was further increased to 300 $\mathrm{mA} \mathrm{cm}{ }^{-2}$ (with $\sim 95 \%$ faradic efficiency) by pressurizing the $\mathrm{CO}_{2}$ inlet (up to $10 \mathrm{bar}$ ). Evenly distributing the $\mathrm{CO}_{2}$ gas among the layers, the electrolyzer operates identically to the sum of multiple single-layer electrolyzer cells. When passing the $\mathrm{CO}_{2}$ gas through the layers consecutively, the $\mathrm{CO}_{2}$ conversion efficiency increased.

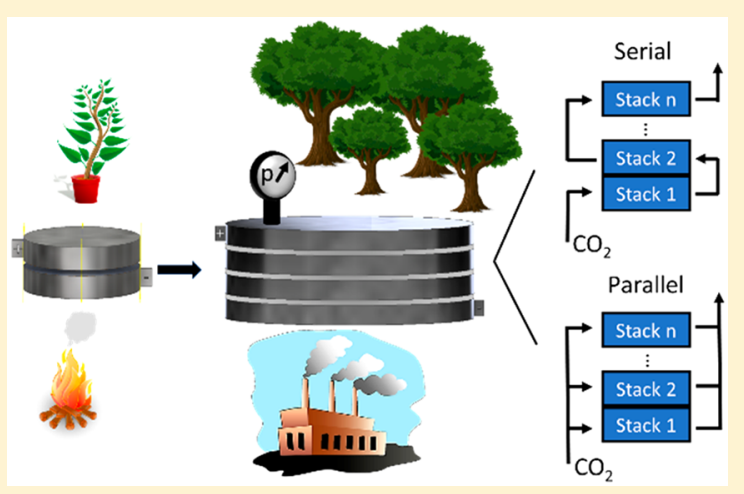
The electrolyzer simultaneously provides high partial current density, low cell voltage $(-3.0 \mathrm{~V})$, high conversion efficiency (up to $40 \%)$, and high selectivity for CO production.

$\mathrm{W}$ ith either considering carbon dioxide as a feedstock for transportation fuels and commodity chemicals or aiming to reduce its atmospheric emission, electrochemical reduction of $\mathrm{CO}_{2}$ (CO2RR) is one of the major scientific and engineering challenges. ${ }^{1,2}$ Various catalysts have been investigated in literally thousands of scientific works, identifying active and selective candidates and revealing important structure-property relationships with regard to catalyst size, shape, morphology, etc. As important examples of CO2RR, selective carbon monoxide formation was demonstrated on Ag electrodes, while multitudes of different alcohols and hydrocarbons form on copper catalysts. ${ }^{3}$ The large differences in the activities and selectivities of different catalysts in CO2RR are better understood by now and are also supported by theoretical studies on the reaction mechanism. ${ }^{4}$

The industrial implementation of this technology necessitates the transformation of $\mathrm{CO}_{2}$ to products at a high rate (i.e., current density, $\mid j_{\text {product }} l>200 \mathrm{~mA} \mathrm{~cm}{ }^{-2}$ ), 5 which is inherently hampered in aqueous solutions by the low solubility of $\mathrm{CO}_{2}$. Continuous-flow gas-fed electrolyzers might offer the only viable technological solution to overcome this limitation. ${ }^{7,8}$ Apart from the high reactant concentration on the catalyst surface ensured by the continuous $\mathrm{CO}_{2}$ flow, it is also crucial to provide a high surface area for the electrochemical reaction. Hence, porous, gas diffusion electrodes (GDEs) are used in these electrolyzers, in which the triple phase boundary among the reactant gas, the catalyst, and the solid ionomer is maximized. ${ }^{9-11}$

To drive CO2RR in an economically feasible way, electrolyzer cells must be developed, which operate (i) at high current density (conversion rate), (ii) at low cell voltage (i.e., high energy efficiency), (iii) with high faradic efficiency (selectivity), and (iv) with high conversion efficiency. Notably, even though these four parameters together describe the overall performance of an electrolyzer cell, very seldom are all of these reported in the scientific literature.

Over the past decade, a remarkable advancement was achieved with continuous-flow electrolyzers, ${ }^{7,8,12,13}$ most importantly with electrolyzers applying a dual (electrolyte + $\mathrm{CO}_{2}$ gas) feed on the cathode (e.g., in microfluidic cells) and electrolyte feed at the anode. ${ }^{14,15}$ Cation $^{16}$ or anion ${ }^{17-20}$

Received: May 26, 2019

Accepted: June 27, 2019

Published: June 27, 2019 
(A)

(B)

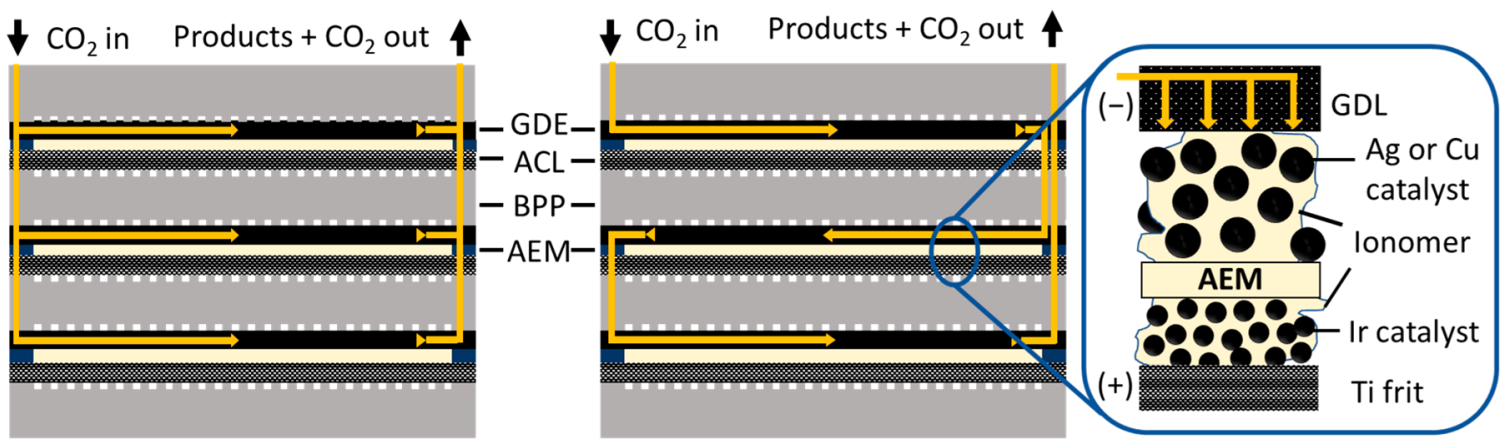

(C)

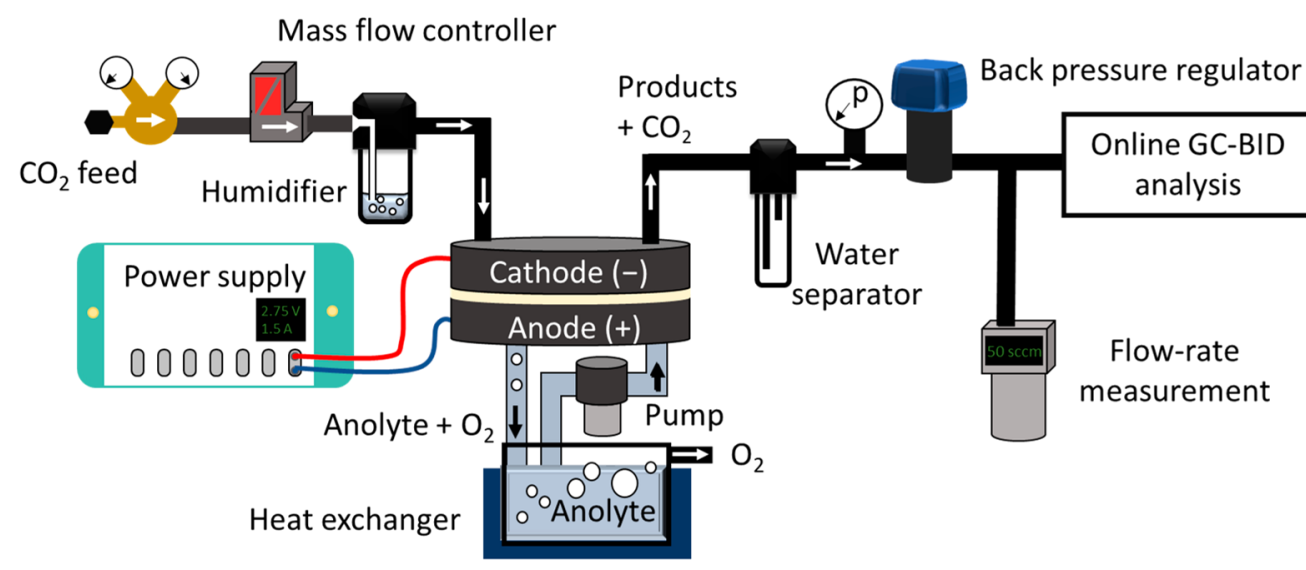

Figure 1. $\mathrm{CO}_{2}$ gas channel structure in an electrolyzer stack consisting of three layers in the (A) parallel and (B) serial connection configurations. BPP: bipolar plate; ACL: anode catalyst layer; GDE: gas diffusion electrode; GDL: gas diffusion layer; AEM: anion exchange membrane. (C) Schematic flowchart of the measurement setup.

exchange membranes, bipolar membranes, ${ }^{21-23}$ (PEM, AEM, and BPM, accordingly), and even an inorganic diaphragm ${ }^{24}$ were proved to be applicable separators between the cell compartments. The effects of several parameters were scrutinized: electrolyte composition (e.g., electrolyte type, concentration, $\mathrm{pH}$, etc.), ${ }^{14,23,25-27}$ structure of the microporous layer, ${ }^{28}$ catalyst morphology, ${ }^{29}$ and immobilizing the catalysts on different high surface area supports. ${ }^{30-32}$ Some of these studies were performed applying pressurized $\mathrm{CO}_{2}$ inlets (although not in the zero-gap configuration), ${ }^{16,25,33}$ further improving the performance. As a result, industrially relevant current densities, above $\left.\right|_{\text {product }} l=200 \mathrm{~mA} \mathrm{~cm}{ }^{-2}$, have become a reality with both $\mathrm{Cu}^{34-38}$ and $\mathrm{Ag}^{30,32,39}$ catalysts. Achieving high $\mathrm{CO}_{2}$ conversion efficiency, however, is a substantial challenge in such electrolyzers because of (i) the typically large gas head space above the GDEs and (ii) the $\mathrm{CO}_{2}$ losses due to its dissolution in the catholyte.

Considerably less attention has been devoted to zero gap membrane electrolyzers, in which $\mathrm{CO}_{2}$ gas is directly fed to the cathode. ${ }^{40-46}$ These cells offer a simple technological solution, in which (i) the cell resistance can be very low (which translates to high energy efficiency), (ii) the inlet can be pressurized relatively easily, (iii) no catholyte is used and, hence, no liquid catholyte circulation loop is required, and finally, (iv) the losses due to $\mathrm{CO}_{2}$ dissolution in the catholyte are minimal. The knowledge gathered with fuel cells and PEM water electrolyzers might contribute to future scale-up of this technology, as these are mature electrochemical technologies with cells of similar structure. Constructing large size and multilayer stacks is a common practice in both abovementioned fields; ${ }^{47,48}$ nonetheless, it has not been demonstrated for $\mathrm{CO}_{2}$ reduction yet. Implementation of this concept to $\mathrm{CO}_{2}$ electrolyzers can accelerate technology development, to scale up electrochemical $\mathrm{CO}_{2}$ reduction to an industrially relevant level. Here we present a zero gap $\mathrm{CO}_{2}$ electrolyzer stack, which consists of multiple electrolyzer layers and can operate with a pressurized $\mathrm{CO}_{2}$ gas feed, without the need for any liquid catholyte. Furthermore, the flexibility of the presented design allows different connections between the layers of the electrolyzer regarding the distribution of the reactant $\mathrm{CO}_{2}$ gas. Connecting the cells in parallel (Figure 1A), the gas is equally distributed among them; hence, pure $\mathrm{CO}_{2}$ is fed to each cathode. On the other hand, when connecting the gas channels in series (Figure 1B), the total gas flux enters the first layer, and the off-gas (remnant $\mathrm{CO}_{2}+$ products) continues to the subsequent layer(s), hence allowing very high conversion efficiencies. From an electric perspective, the cells are connected in series in both cases (i.e., the same current flows through them). While the presented cell is completely scalable, the presented data were recorded with a cell which contained up to three electrolyzer units (having $61 \mathrm{~cm}^{2} /$ cell active area), connected through bipolar plates. For testing the operation of the electrolyzer cell and to analyze the formed products, a test station was designed (Figure 1C) that was used throughout the experiments presented here. Further information regarding the cell (Figure S1) and the electrolyzer station is provided in the Supporting Information. 

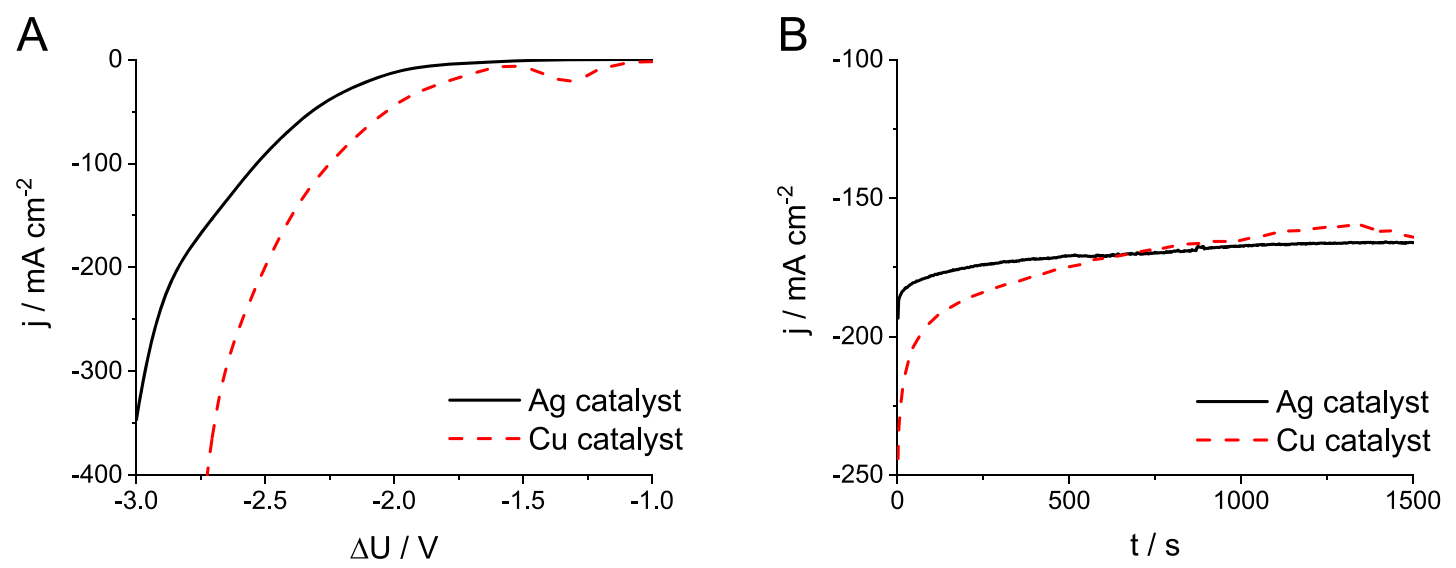

Figure 2. (A) LSV curves recorded at $\nu=10 \mathrm{mV} \mathrm{s}^{-1}$ sweep rate and (B) chronoamperometric curves recorded at $\Delta U=-2.75 \mathrm{~V}$ with different catalyst containing cathode GDEs. The cathode compartment was purged with humidified $\mathrm{CO}_{2}$ at a flow rate of $u=150 \mathrm{~cm}^{3}$ min ${ }^{-1}$.
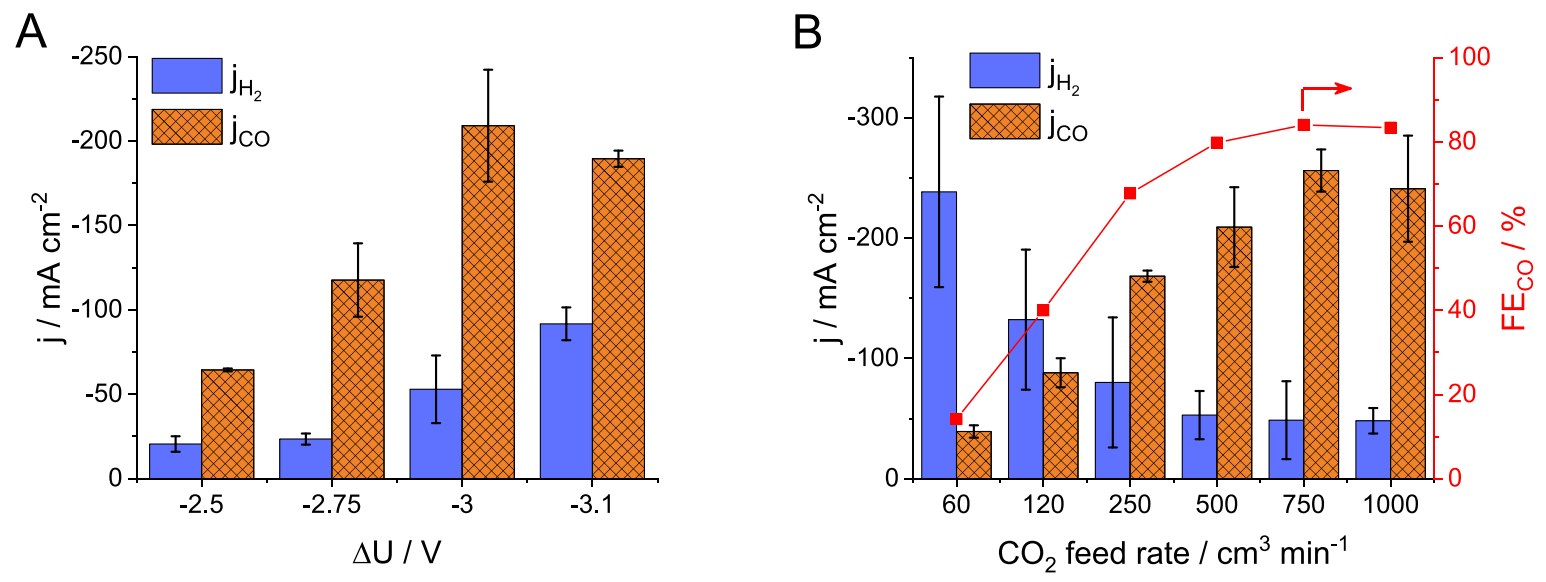

Figure 3. Partial current densities for $\mathrm{CO}$ and $\mathrm{H}_{2}$ formation (A) at different cell voltages, at a $\mathrm{CO}_{2}$ feed rate of $u=500 \mathrm{~cm}^{3} \mathrm{~min}{ }^{-1}$, and $(B)$ at $\Delta U=-3.00 \mathrm{~V}$, as a function of the $\mathrm{CO}_{2}$ feed rate to the cathode.

Electrochemical $\mathrm{CO}_{2}$ Reduction to Gas Phase Products Using Ag and $\mathrm{Cu}$ Catalysts. Ag nanoparticles and electrodeposited $\mathrm{Cu}$ nanocubes, ${ }^{49,50}$ immobilized on separate gas diffusion layers, were used to validate the operation of the electrolyzer in a single layer setup (see SEM images in Figures S2 and S3). The onset of a faradic process, read at $10 \mathrm{~mA} \mathrm{~cm}^{-2}$ current density, was observed at $-1.71 \mathrm{~V}$ with the $\mathrm{Cu}$ nanocube catalyst and $-2.01 \mathrm{~V}$ with the $\mathrm{Ag}$ nanoparticles on the linear sweep voltammetry curves (LSVs, Figure 2A). At voltages between -1.2 and $-1.5 \mathrm{~V}$, a reduction peak, related to the reduction of copper oxide, was observed for the $\mathrm{Cu}$ nanocube catalyst in line with our previous study. ${ }^{51}$

Chronoamperometric curves were recorded for both catalysts at $-2.75 \mathrm{~V}$, where a stable operation was observed (Figure 2B). Gas chromatographic analysis of the composition of the product stream during electrolysis showed the formation of $\mathrm{C}_{2} \mathrm{H}_{4}, \mathrm{CH}_{4}, \mathrm{CO}$, and $\mathrm{H}_{2}$ for the $\mathrm{Cu}$ nanocube catalyst, while only $\mathrm{CO}$ and $\mathrm{H}_{2}$ formed on the Ag catalyst (Figure S4A,B). The cumulative faradic efficiency calculated for these products approached $100 \%$ in both cases, which suggests that the possible formation of other products is negligible. These results agree with earlier literature reports ${ }^{30,34}$ and confirm that the $\mathrm{CO}_{2}$ gas enters the GDE and reaches the catalyst surface; hence, the structure of the electrolyzer cell is appropriate for such studies. In the following, the detailed study on the effect of different experimental conditions and cell parameters is presented for the silver nanoparticle catalyst. Notably, in this study we focus on the operation of the electrolyzer; hence, the cathode GDEs were formed from commercially available components (GDL, Ag catalyst, ionomer), based on earlier reports. $^{17,19,20}$

Effect of the Operational Parameters. The effect of the cell voltage on the conversion rate and selectivity of CO2RR was investigated at constant $\mathrm{CO}_{2}$ feed rate (Figure 3A). Increasing the cell voltage leads to an increase in the overall current density. The $\mathrm{CO}$ partial current density $\left(j_{\mathrm{CO}}\right)$ peaks at $-3 \mathrm{~V}$, while the partial current density for $\mathrm{H}_{2}$ production $\left(j_{\mathrm{H}_{2}}\right)$ grows monotonously with the cell voltage; hence, the hydrogen evolution reaction (HER) becomes dominant at higher cell voltages.

Regarding the $\mathrm{CO}_{2}$ gas feed rate, HER is dominant over CO2RR at lower values. The $j_{\mathrm{H}_{2}}$ decreases and reaches a minimum value, while $j_{\mathrm{CO}}$ (together with the faradic efficiency of $\mathrm{CO}$ formation) increases and then peaks with the increasing $\mathrm{CO}_{2}$ feed rate. Importantly, a partial current density for $\mathrm{CO}$ formation above $-250 \mathrm{~mA} \mathrm{~cm} \mathrm{~cm}^{-2}$ was achieved (this is an average of multiple measurements on five different cell assemblies, where the champion cell resulted in $-300 \mathrm{~mA}$ $\mathrm{cm}^{-2}$ ), while the faradic efficiency $\left(\mathrm{FE}_{\mathrm{CO}}\right)$ was around $85 \%$. We emphasize that only hydrogen was formed as a byproduct; no liquid or other gas phase products were detected. This simplifies the further processing of the product stream, as this syngas mixture can be directly used in the Fischer-Tropsch 


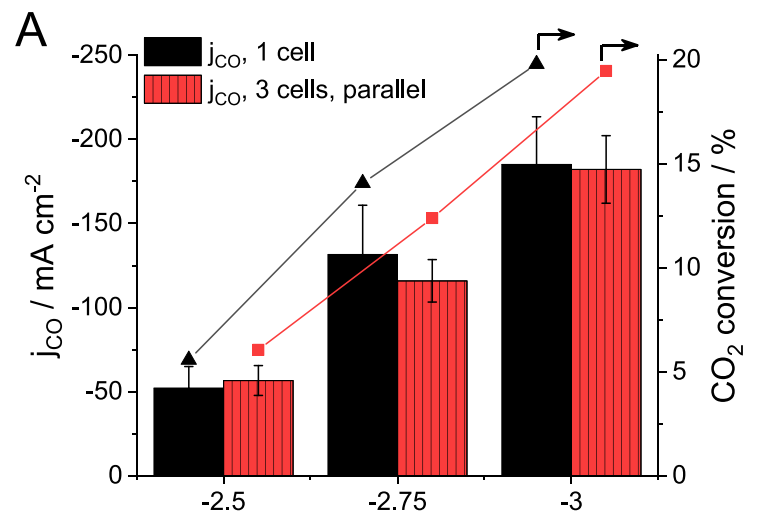

$\Delta \mathrm{U} /$ stack / V
B

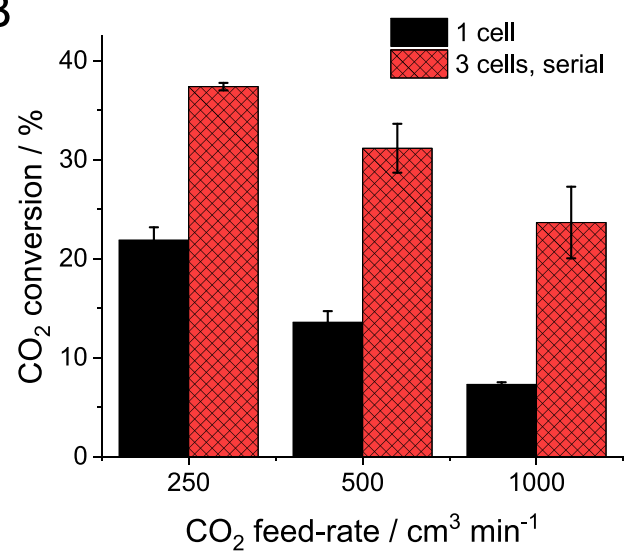

Figure 4. (A) $\mathrm{CO}$ partial current density and $\mathrm{CO}_{2}$ conversion with a one-cell electrolyzer and an electrolyzer stack consisting of three cells, in the parallel configuration during electrolysis at different cell voltages with $433 \mathrm{~cm}^{3} \mathrm{~min}^{-1} \mathrm{CO}_{2}$ feed rate per cell at the cathode. (B) $\mathrm{CO}_{2}$ conversion with a single-cell electrolyzer and an electrolyzer stack consisting of three cells, in the serial configuration, at different $\mathrm{CO}_{2}$ feed rates, at $\Delta U=-2.75 \mathrm{~V} /$ cell.
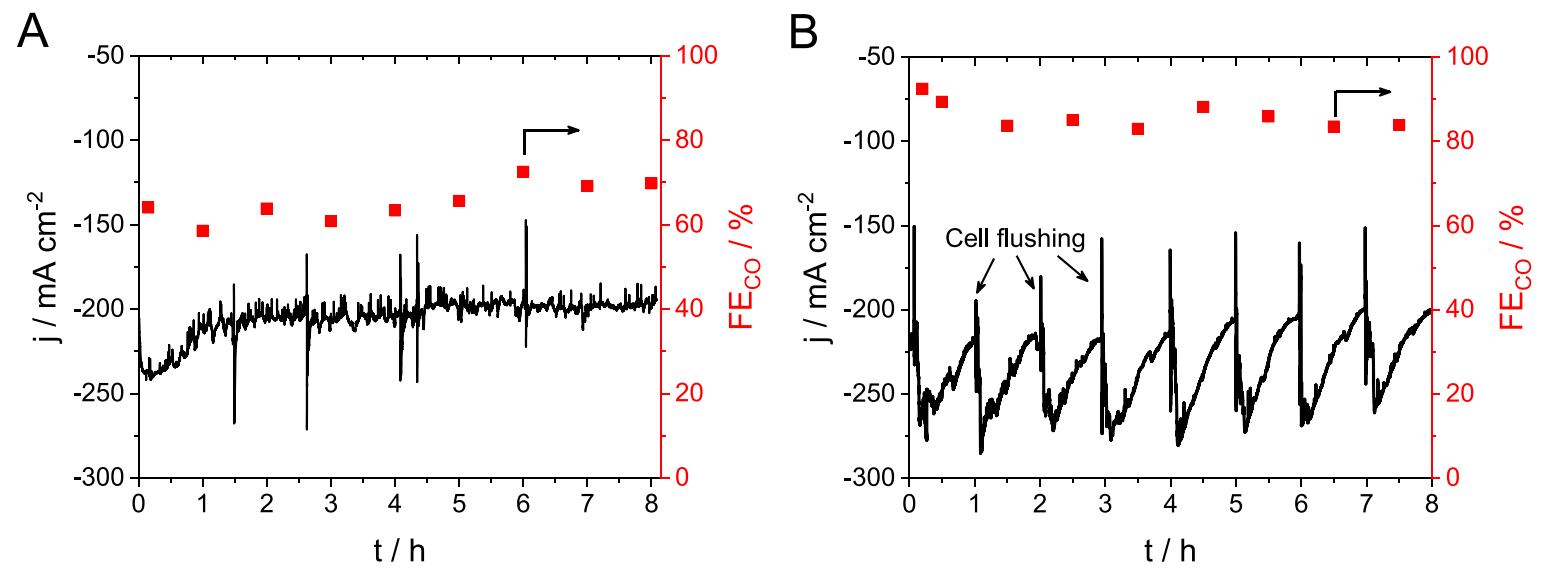

Figure 5. Chronoamperometric curves recorded at $\Delta U=-3.00 \mathrm{~V}$ with $u=750 \mathrm{~cm}^{3} \mathrm{~min}^{-1} \mathrm{CO}_{2}$ flow rate, humidified at $(\mathrm{A}) T=85{ }^{\circ} \mathrm{C}$ and (B) $T=60^{\circ} \mathrm{C}$, while the cell was rinsed with ca. $50 \mathrm{~cm}^{3}$ deionized water at the beginning of each hour. The CO faradic efficiency values were calculated from the analysis of the gas products by gas chromatography.

synthesis, after adjusting the proper $\mathrm{CO}$ to $\mathrm{H}_{2}$ ratio using an external hydrogen source, such as a water electrolyzer cell. ${ }^{52}$

Electrolysis of $\mathrm{CO}_{2}$ to $\mathrm{CO}$ in a Multilayer Electrolyzer Stack. Assembling multilayer electrolyzer stacks, in which the cathode compartments are connected in parallel, is a way to increase the electrochemically active surface area without having to increase the lateral size of the electrolyzer. Comparing the results obtained with a single-cell electrolyzer and a stack cell consisting of three layers in parallel connection, the partial current density for $\mathrm{CO}$ formation and the $\mathrm{CO}_{2}$ conversion were very similar at all studied cell voltages (Figure 4A). This indicates that the $\mathrm{CO}_{2}$ gas is evenly split among the layers in the stack and all individual cells operate with the same performance. We note again that the layers are connected in series electrically, and therefore the overall stack voltage can be controlled. Measuring the individual cell voltages during electrolysis, we found that the overall stack voltage is split evenly among them. Furthermore, the onset voltage (note that the stack voltage is normalized with the number of electrolyzer layers) and currents on the LSV curves recorded with a singlecell electrolyzer and a 3-layer electrolyzer stack in the parallel configuration are also comparable (Figure S4). The faradic efficiencies were also very similar: around $85 \%$ at lower cell voltages in both cases, which decreased to $75 \%$ at $-3.0 \mathrm{~V} /$ layer voltage. From a technological perspective, assembling multiplelayer electrolyzer stacks instead of parallelly operating multiple, single-cell electrolyzers decreases the capital investment costs, as the electrolyzer frame and the anolyte circulation loop only has to be built once and any further cell only requires an extra bipolar plate, insulation, and a membrane electrode assembly.

Connecting the cells in series is a completely different story. In this case, the off-gas of the first electrolyzer layer is fed to the subsequent layers, where (part) of the remnant $\mathrm{CO}_{2}$ is transformed to products. Comparing the results measured with an electrolyzer stack consisting of three cells in serial configuration with that recorded for a single-layer cell, a large increase (ca. 70\%) in $\mathrm{CO}_{2}$ conversion was achieved even at low $\mathrm{CO}_{2}$ feed rates, where the $\mathrm{CO}_{2}$ conversion is already over $20 \%$ for the single-cell electrolyzer; hence, a $\mathrm{CO}_{2}$ stream, diluted with $\mathrm{CO}$ and $\mathrm{H}_{2}$, reached the subsequent layers of the stack (Figure 4B). When increasing the gas feed rate, the difference increases drastically. At the highest studied gas feed rate, the $\mathrm{CO}_{2}$ conversion was three times higher in the electrolyzer stack, indicating the comparable operation of three individual cells. Furthermore, the faradic efficiency for $\mathrm{CO}$ production was above $95 \%$ in this case. We note that achieving high conversion decreases the separation and handling costs 
A

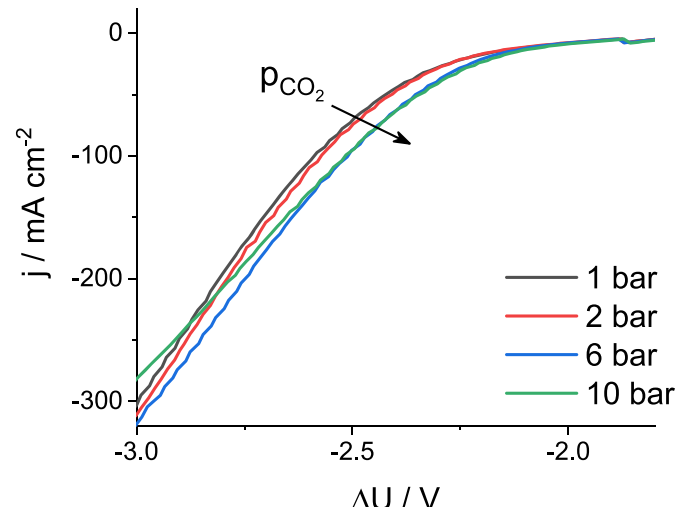

B

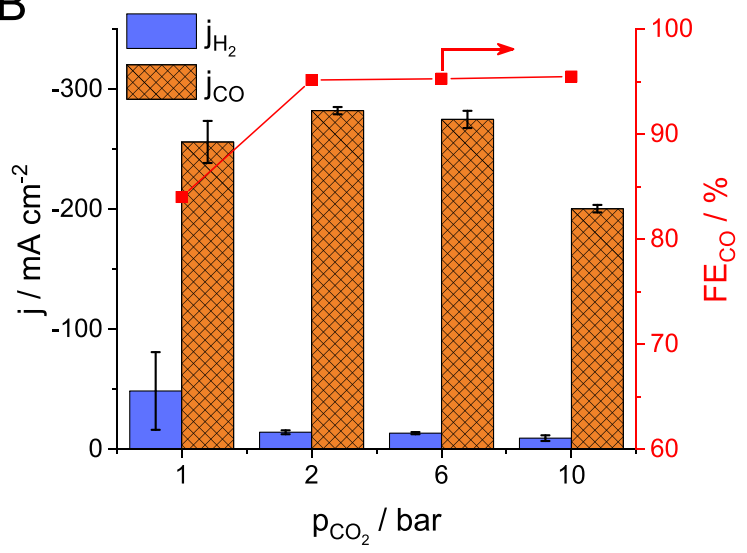

Figure 6. (A) LSV curves recorded at $\nu=10 \mathrm{mV} \mathrm{s}^{-1}$ sweep rate and (B) partial current densities for CO and $\mathrm{H}_{2}$ formation, and the ratio of these during electrolysis at $\Delta U=-3.00 \mathrm{~V}$, both as a function of the differential $\mathrm{CO}_{2}$ pressure. The cathode compartment was purged with humidified $\mathrm{CO}_{2}$ at a flow rate of $u=750 \mathrm{ncm}^{3} \min ^{-1}$.

and, therefore, increases the value of the final gas mixture, strongly supporting the industrial implementation of CO2RR.

Stationary Operation of the $\mathrm{CO}_{2}$ Electrolyzer. When using anion exchange membranes and concentrated $\mathrm{KOH}$ solution in $\mathrm{CO} 2 \mathrm{RR}$, the precipitation of $\mathrm{K}_{2} \mathrm{CO}_{3}$ at the cathode side is a common issue, decreasing the performance of the electrolyzer by blocking the gas channels and the active catalyst sites. ${ }^{53}$ Different approaches can be envisioned to overcome this challenge. The first and most obvious one is to use pure deionized water as anolyte instead of strong alkaline solutions. This tactic is feasible for some AEMs, ${ }^{54}$ and with the rapid development in this field, we envision that other membranes will also be available to be used with pure water (just like Nafion in water electrolyzer cells). For cells working with $\mathrm{KOH}$, dissolving the precipitated $\mathrm{K}_{2} \mathrm{CO}_{3}$ during operation must be solved (without disassembling the cell), but as of yet, no ultimate engineering solution has been developed.

We present two possible avenues here. One is to increase the temperature of the humidified $\mathrm{CO}_{2}$ inlet and, thus, continuously feed more water vapor into the cell (Figure 5A). The other approach is to periodically flush the cell with liquid water (Figure 5B). In the first case, the temperature of the water humidifier was increased to $85{ }^{\circ} \mathrm{C}$, which led to the stable operation of the cell after a $30 \mathrm{~min}$ transient period at the beginning of the experiment. The $\mathrm{FE}_{\mathrm{CO}}$ however, was considerably smaller (65-70\%) throughout the measurement, compared to previous studies at lower inlet temperature (Figure 3). This trend can be attributed to the increased amount of water in the cell (i.e., higher probability of the HER). On the other hand, when the humidification was performed at lower temperature, a continuous current decay was observed during the measurements, due to $\mathrm{K}_{2} \mathrm{CO}_{3}$ precipitation. Therefore, the cell was flushed with deionized water at the beginning of each hour for $10 \mathrm{~s}$. This rapid washing step healed the electrolyzer stack and restored the current to its original value $\left(\sim 250-275 \mathrm{~mA} \mathrm{~cm}^{-2}\right)$. The $\mathrm{FE}_{\mathrm{CO}}$ was around $85 \%$ through the whole electrolysis. Comparing the current values at the end and at the beginning of each hour, no systematic decrease and, hence, no irreversible degradation were observed during the $8 \mathrm{~h}$. Overall, both approaches avoid the accumulation of $\mathrm{K}_{2} \mathrm{CO}_{3}$ precipitate. In the first case, the elevated temperature increases both the water amount in the $\mathrm{CO}_{2}$ stream and the solubility of $\mathrm{K}_{2} \mathrm{CO}_{3}$. In the second case, $\mathrm{K}_{2} \mathrm{CO}_{3}$ is washed out before larger plaque could build up.
Pressurized Electrolysis of $\mathrm{CO}_{2}$ to $\mathrm{CO}$. Performing CO2RR with a pressurized $\mathrm{CO}_{2}$ inlet is technologically important from multiple aspects. Some of the industrial $\mathrm{CO}_{2}$ point sources are already under pressure, so the technology can be easily implemented. In addition, a pressurized product stream can be more easily transported, handled, and utilized.

Pressurizing the cathodic $\mathrm{CO}_{2}$ feed leads to the positive shift of the onset potential on the LSV curves (Figure 6A), indicating a thermodynamically more favored CO2RR process. The current also increases slightly with the applied pressure. In line with this, the $\mathrm{CO}$ formation partial current density during potentiostatic measurements initially increases from $-250 \mathrm{~mA}$ $\mathrm{cm}^{-2}$ above $-285 \mathrm{~mA} \mathrm{~cm}^{-2}$ with the applied pressure and then decreases at 10 bar (Figure $6 \mathrm{~B}$ ). The decrease at high pressure might be related to the enhanced crossover of $\mathrm{CO}_{2}$ (and possibly $\mathrm{CO}$ ) through the employed anion exchange membrane; a notable decrease (above 20\%) was observed in the gas flow rate during these measurements, even without any electrochemical polarization. More importantly, the selectivity for $\mathrm{CO}$ formation increases remarkably under pressure; a faradic efficiency of $95 \%$ (as compared to $\sim 85 \%$ at atmospheric pressure) was found for CO2RR even at 1 bar $\mathrm{CO}_{2}$ overpressure, which is not influenced by the further pressure increase. The operation of the electrolyzer was stable under intermediate pressure (4-6 bar) during the tests, for tens of hours.

The effect of pressure on the electrochemical properties of the electrolyzer cell is rather complex. The most important factors are the following: (i) the applied pressure presses the GDE on the membrane surface, hence ensuring better contact between them, (ii) the $\mathrm{CO}_{2}$ gas is forced to enter into the GDE structure, (iii) smaller relative amounts of water enter the cell with the humidified, pressurized $\mathrm{CO}_{2}$ stream, and (iv) the concentration (activity) of the $\mathrm{CO}_{2}$ increases. As one can see, some of these effects are simply mechanical while others are chemical, and it is not trivial to deconvolute them.

To further emphasize the complex effect of pressure, measurements similar to what is shown Figure 6 were performed with an electrolyzer built of the same components, but which was significantly underperforming compared to the average cells. Surprisingly, the effect of pressure was much larger in this case! A great current increase was seen in the currents on the LSV curves with increasing pressure (Figure 7A). The $\mathrm{j}_{\mathrm{CO}}$ showed a volcano type dependency, while the 
A

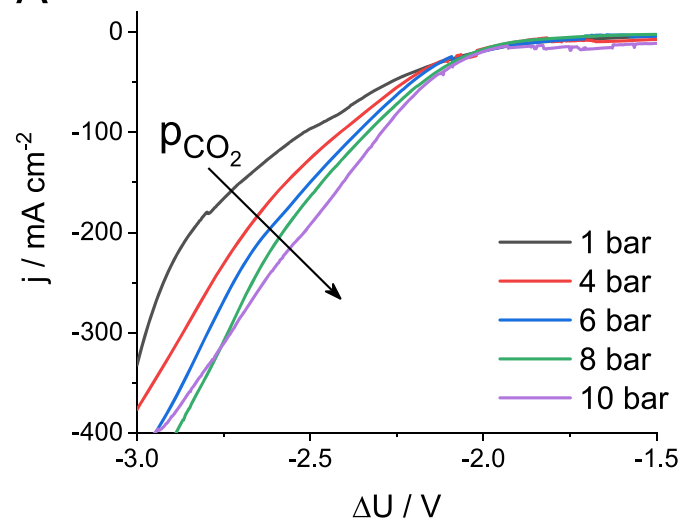

B

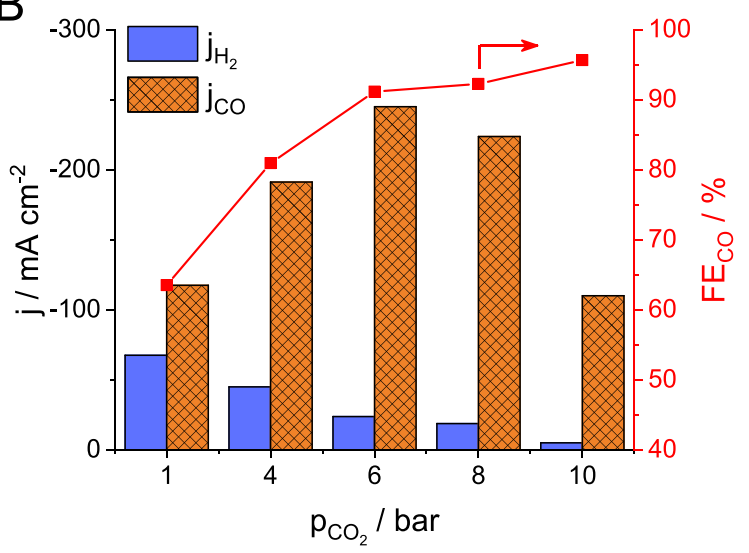

Figure 7. (A) LSV curves recorded at $\nu=10 \mathrm{mV} \mathrm{s}^{-1}$ sweep rate and (B) partial current densities for $\mathrm{CO}$ and $\mathrm{H}_{2}$ formation and the ratio of these during electrolysis at $\Delta U=-2.75 \mathrm{~V}$, both as a function of the differential $\mathrm{CO}_{2}$ pressure for a cell underperforming at atmospheric pressure. The cathode compartment was purged with humidified $\mathrm{CO}_{2}$ at a flow rate of $u=750 \mathrm{ncm}^{3} \mathrm{~min}^{-1}$.

reaction selectivity increased continuously with the pressure (Figure $7 \mathrm{~B}$ ). Interestingly, the $\mathrm{j}_{\mathrm{CO}}$ and the $\mathrm{FE}_{\mathrm{CO}}$ is very similar to what was shown for the well performing electrolyzer cells at intermediate pressure ( $p=6 \mathrm{bar})$.

Two important conclusions can be drawn from these observations. First, when reporting the effect of pressure, it is very important to investigate and exclude all trivial effects (e.g., the compression of the GDE) and study cells which already have good performance at atmospheric pressure. Second, an electrolyzer cell underperforming at atmospheric pressure, in which the dimensions of the components are not perfectly matched, can function the same way under pressure as a properly assembled cell.

In summary, we developed a direct $\mathrm{CO}_{2}$ gas-fed, zero gap electrolyzer cell, which can operate with different catalysts. By employing GDEs formed of commercially available components, $\mathrm{CO}$ formation partial current densities above $-250 \mathrm{~mA}$ $\mathrm{cm}^{-2}$ were routinely achieved. By pressurizing the $\mathrm{CO}_{2}$ inlet, this could be increased close to $-300 \mathrm{~mA} \mathrm{~cm}^{-2}$, and the $\mathrm{CO}$ to $\mathrm{H}_{2}$ ratio was extraordinarily high in this case (above 20). The assembly and operation of a multilayer electrolyzer stack of any $\mathrm{CO}_{2}$ electrolyzer was demonstrated for the first time. We highlighted two possible scenarios for assembling multiple cells in an electrolyzer stack: one in which the electrolyzer layers are connected in parallel in terms of the gas feed, where hence the operation of electrolyzer stack is identical to the sum of multiple single-cell electrolyzers, and another one, where, when connecting the layers in series, the conversion rate increased significantly compared to a single-cell electrolyzer. These insights might trigger further development in scaling-up this fledging technology, which will bring us closer to its industrial implementation.

\section{ASSOCIATED CONTENT}

\section{S Supporting Information}

The Supporting Information is available free of charge on the ACS Publications website at DOI: 10.1021/acsenergylett.9b01142.

Experimental details and the following additional data: schematic structure of the electrolyzer stack, SEM images of the electrodeposited $\mathrm{Cu}$ nanocube layers, SEM images of the spray-coated Ag nanoparticle layers, gas chromatographs recorded during potentiostatic measurements with the $\mathrm{Ag}$ and $\mathrm{Cu}$ catalysts, and additional electrochemical measurements with the electrolyzer stack (PDF)

\section{AUTHOR INFORMATION}

\section{Corresponding Authors}

*E-mail: janaky@chem.u-szeged.hu (C. Janáky).

*E-mail: endrodib@chem.u-szeged.hu (B. Endrōdi).

ORCID ${ }^{\circ}$

B. Endrödi: 0000-0003-3237-9222

C. Janáky: 0000-0001-5965-5173

Notes

The authors declare the following competing financial interest(s): There is a patent application pending, filed by the authors of this paper and their institutions. Application number: PCT/HU2019/095001. Specifically, the patent application covers the details of the cell architecture, description of the individual components of the cell, and the electrolysis process.

\section{ACKNOWLEDGMENTS}

This project has received funding from the European Research Council (ERC) under the European Union's Horizon 2020 research and innovation programme (Grant Agreement No. 716539). E.K. acknowledges the support of the New National Excellence Program of the Ministry of Human Capacities (Grant UNKP-18-3). This research was also supported by the "Széchenyi 2020" program in the framework of the GINOP2.2.1-15-2017-00041 project.

\section{REFERENCES}

(1) Chen, C.; Khosrowabadi Kotyk, J. F.; Sheehan, S. W. Progress toward Commercial Application of Electrochemical Carbon Dioxide Reduction. Chem. 2018, 4 (11), 2571-2586.

(2) De Luna, P.; Hahn, C.; Higgins, D.; Jaffer, S. A.; Jaramillo, T. F.; Sargent, E. H. What Would It Take for Renewably Powered Electrosynthesis to Displace Petrochemical Processes? Science 2019, 364 (6438), No. eaav3506.

(3) Jones, J. P.; Prakash, G. K. S.; Olah, G. A. Electrochemical $\mathrm{CO}_{2}$ Reduction: Recent Advances and Current Trends. Isr. J. Chem. 2014, 54 (10), 1451-1466.

(4) Kortlever, R.; Shen, J.; Schouten, K. J. P.; Calle-Vallejo, F.; Koper, M. T. M. Catalysts and Reaction Pathways for the 
Electrochemical Reduction of Carbon Dioxide. J. Phys. Chem. Lett. 2015, 6 (20), 4073-4082.

(5) Verma, S.; Kim, B.; Jhong, H.-R.; Ma, S.; Kenis, P. J. A. A GrossMargin Model for Defining Technoeconomic Benchmarks in the Electroreduction of $\mathrm{CO}_{2}$. ChemSusChem 2016, 9 (15), 1972-1979.

(6) Jouny, M.; Luc, W.; Jiao, F. General Techno-Economic Analysis of $\mathrm{CO}_{2}$ Electrolysis Systems. Ind. Eng. Chem. Res. 2018, 57 (6), 21652177.

(7) Endrődi, B.; Bencsik, G.; Darvas, F.; Jones, R.; Rajeshwar, K.; Janáky, C. Continuous-Flow Electroreduction of Carbon Dioxide. Prog. Energy Combust. Sci. 2017, 62, 133-154.

(8) Merino-Garcia, I.; Alvarez-Guerra, E.; Albo, J.; Irabien, A. Electrochemical Membrane Reactors for the Utilisation of Carbon Dioxide. Chem. Eng. J. 2016, 305, 104-120.

(9) Higgins, D.; Hahn, C.; Xiang, C.; Jaramillo, T. F.; Weber, A. Z. Gas-Diffusion Electrodes for Carbon Dioxide Reduction: A New Paradigm. ACS Energy Lett. 2019, 4 (1), 317-324.

(10) Liu, K.; Smith, W. A.; Burdyny, T. Introductory Guide to Assembling and Operating Gas Diffusion Electrodes for Electrochemical $\mathrm{CO}_{2}$ Reduction. ACS Energy Lett. 2019, 4 (3), 639-643.

(11) Burdyny, T.; Smith, W. A. $\mathrm{CO}_{2}$ Reduction on Gas-Diffusion Electrodes and Why Catalytic Performance Must Be Assessed at Commercially-Relevant Conditions. Energy Environ. Sci. 2019, 12, $1442-1453$

(12) Weekes, D. M.; Salvatore, D. A.; Reyes, A.; Huang, A.; Berlinguette, C. P. Electrolytic $\mathrm{CO}_{2}$ Reduction in a Flow Cell. Acc. Chem. Res. 2018, 51 (4), 910-918.

(13) Jeanty, P.; Scherer, C.; Magori, E.; Wiesner-Fleischer, K.; Hinrichsen, O.; Fleischer, M. Upscaling and Continuous Operation of Electrochemical $\mathrm{CO}_{2}$ to $\mathrm{CO}$ Conversion in Aqueous Solutions on Silver Gas Diffusion Electrodes. J. CO2 Util. 2018, 24, 454-462.

(14) Whipple, D. T.; Finke, E. C.; Kenis, P. J. A. Microfluidic Reactor for the Electrochemical Reduction of Carbon Dioxide: The Effect of pH. Electrochem. Solid-State Lett. 2010, 13 (9), B109.

(15) Dufek, E. J.; Lister, T. E.; Mcllwain, M. E. Bench-Scale Electrochemical System for Generation of CO and Syn-Gas. J. Appl. Electrochem. 2011, 41 (6), 623-631.

(16) Dufek, E. J.; Lister, T. E.; Stone, S. G.; McIlwain, M. E. Operation of a Pressurized System for Continuous Reduction of $\mathrm{CO}_{2}$. J. Electrochem. Soc. 2012, 159 (9), F514-F517.

(17) Kaczur, J. J.; Yang, H.; Liu, Z.; Sajjad, S. D.; Masel, R. I. Carbon Dioxide and Water Electrolysis Using New Alkaline Stable Anion Membranes. Front. Chem. 2018, 6, 263.

(18) Lee, J.; Lim, J.; Roh, C.-W.; Whang, H. S.; Lee, H. Electrochemical $\mathrm{CO}_{2}$ Reduction Using Alkaline Membrane Electrode Assembly on Various Metal Electrodes. J. CO2 Util. 2019, 31, 244250.

(19) Kutz, R. B.; Chen, Q.; Yang, H.; Sajjad, S. D.; Liu, Z.; Masel, I. R. Sustainion Imidazolium-Functionalized Polymers for Carbon Dioxide Electrolysis. Energy Technology 2017, 5, 929-936.

(20) Yang, H.; Kaczur, J. J.; Sajjad, S. D.; Masel, R. I. Electrochemical Conversion of $\mathrm{CO}_{2}$ to Formic Acid Utilizing Sustainion ${ }^{\mathrm{TM}}$ Membranes. J. CO2 Util. 2017, 20, 208-217.

(21) Li, Y. C.; Zhou, D.; Yan, Z.; Gonçalves, R. H.; Salvatore, D. A.; Berlinguette, C. P.; Mallouk, T. E. Electrolysis of $\mathrm{CO}_{2}$ to Syngas in Bipolar Membrane-Based Electrochemical Cells. ACS Energy Lett. 2016, 1 (6), 1149-1153.

(22) Salvatore, D. A.; Weekes, D. M.; He, J.; Dettelbach, K. E.; Li, Y. C.; Mallouk, T. E.; Berlinguette, C. P. Electrolysis of Gaseous $\mathrm{CO}_{2}$ to CO in a Flow Cell with a Bipolar Membrane. ACS Energy Lett. 2018, 3 (1), 149-154.

(23) Dinh, C. T.; García De Arquer, F. P.; Sinton, D.; Sargent, E. H. High Rate, Selective, and Stable Electroreduction of $\mathrm{CO}_{2}$ to $\mathrm{CO}$ in Basic and Neutral Media. ACS Energy Lett. 2018, 3 (11), 2835-2840.

(24) Haas, T.; Krause, R.; Weber, R.; Demler, M.; Schmid, G. Technical Photosynthesis Involving $\mathrm{CO}_{2}$ Electrolysis and Fermentation. Nat. Catal. 2018, 1 (1), 32-39.

(25) Gabardo, C. M.; Seifitokaldani, A.; Edwards, J. P.; Dinh, C.-T.; Burdyny, T.; Kibria, M. G.; O’Brien, C. P.; Sargent, E. H.; Sinton, D.
Combined High Alkalinity and Pressurization Enable Efficient $\mathrm{CO}_{2}$ Electroreduction to CO. Energy Environ. Sci. 2018, 11 (9), 25312539.

(26) Ma, L.; Fan, S.; Zhen, D.; Wu, X.; Liu, S.; Lin, J.; Huang, S.; Chen, W.; He, G. Electrochemical Reduction of $\mathrm{CO}_{2}$ in Proton Exchange Membrane Reactor: The Function of Buffer Layer. Ind. Eng. Chem. Res. 2017, 56 (37), 10242-10250.

(27) Verma, S.; Lu, X.; Ma, S.; Masel, R. I.; Kenis, P. J. A. The Effect of Electrolyte Composition on the Electroreduction of $\mathrm{CO}_{2}$ to $\mathrm{CO}$ on Ag Based Gas Diffusion Electrodes. Phys. Chem. Chem. Phys. 2016, 18 (10), 7075-7084.

(28) Kim, B.; Hillman, F.; Ariyoshi, M.; Fujikawa, S.; Kenis, P. J. A. Effects of Composition of the Micro Porous Layer and the Substrate on Performance in the Electrochemical Reduction of $\mathrm{CO}_{2}$ to CO. J. Power Sources 2016, 312, 192-198.

(29) Hursán, D.; Samu, A. A.; Janovák, L.; Artyushkova, K.; Asset, T.; Atanassov, P.; Janáky, C. Morphological Attributes Govern Carbon Dioxide Reduction on N-Doped Carbon Electrodes. Joule 2019, DOI: $10.1016 /$ j.joule.2019.05.007.

(30) Ma, S.; Luo, R.; Gold, J. I.; Yu, A. Z.; Kim, B.; Kenis, P. J. A. Carbon Nanotube Containing Ag Catalyst Layers for Efficient and Selective Reduction of Carbon Dioxide. J. Mater. Chem. A 2016, 4 (22), 8573-8578.

(31) Möller, T.; Ju, W.; Bagger, A.; Wang, X.; Luo, F.; Ngo Thanh, T.; Varela, A. S.; Rossmeisl, J.; Strasser, P. Efficient $\mathrm{CO}_{2}$ to $\mathrm{CO}$ Electrolysis on Solid $\mathrm{Ni}-\mathrm{N}-\mathrm{C}$ Catalysts at Industrial Current Densities. Energy Environ. Sci. 2019, 12 (2), 640-647.

(32) Ma, S.; Lan, Y.; Perez, G. M. J.; Moniri, S.; Kenis, P. J. A. Silver Supported on Titania as an Active Catalyst for Electrochemical Carbon Dioxide Reduction. ChemSusChem 2014, 7 (3), 866-874.

(33) Ramdin, M.; Morrison, A. R. T.; De Groen, M.; Van Haperen, R.; De Kler, R.; Van Den Broeke, L. J. P.; Trusler, J. P. M.; De Jong, W.; Vlugt, T. J. H. High Pressure Electrochemical Reduction of $\mathrm{CO}_{2}$ to Formic Acid/Formate: A Comparison between Bipolar Membranes and Cation Exchange Membranes. Ind. Eng. Chem. Res. 2019, 58 (5), 1834-1847.

(34) Lan, Y.; Gai, C.; Kenis, P. J. A.; Lu, J. Electrochemical Reduction of Carbon Dioxide on $\mathrm{Cu} / \mathrm{CuO}$ Core/Shell Catalysts. ChemElectroChem 2014, 1 (9), 1577-1582.

(35) Dinh, C.; Burdyny, T.; Kibria, M. G.; Seifitokaldani, A.; Gabardo, C. M.; García de Arquer, F. P.; Kiani, A.; Edwards, J. P.; De Luna, P.; Bushuyev, O. S.; et al. $\mathrm{CO}_{2}$ Electroreduction to Ethylene via Hydroxide-Mediated Copper Catalysis at an Abrupt Interface. Science 2018, 360 (6390), 783-787.

(36) Ma, S.; Sadakiyo, M.; Luo, R.; Heima, M.; Yamauchi, M.; Kenis, P. J. A. One-Step Electrosynthesis of Ethylene and Ethanol from $\mathrm{CO}_{2}$ in an Alkaline Electrolyzer. J. Power Sources 2016, 301, 219-228.

(37) Hoang, T. T. H.; Ma, S.; Gold, J. I.; Kenis, P. J. A.; Gewirth, A. A. Nanoporous Copper Films by Additive-Controlled Electrodeposition: $\mathrm{CO}_{2}$ Reduction Catalysis. ACS Catal. 2017, 7 (5), $3313-3321$.

(38) Mistry, H.; Varela, A. S.; Bonifacio, C. S.; Zegkinoglou, I.; Sinev, I.; Choi, Y. W.; Kisslinger, K.; Stach, E. A.; Yang, J. C.; Strasser, P.; et al. Highly Selective Plasma-Activated Copper Catalysts for Carbon Dioxide Reduction to Ethylene. Nat. Commun. 2016, 7, 12123.

(39) Ma, S.; Liu, J.; Sasaki, K.; Lyth, S. M.; Kenis, P. J. A. Carbon Foam Decorated with Silver Nanoparticles for Electrochemical $\mathrm{CO}_{2}$ Conversion. Energy Technol. 2017, 5 (6), 861-863.

(40) Delacourt, C.; Ridgway, P. L.; Kerr, J. B.; Newman, J. Design of an Electrochemical Cell Making Syngas $\left(\mathrm{CO}+\mathrm{H}_{2}\right)$ from $\mathrm{CO}_{2}$ and $\mathrm{H}_{2} \mathrm{O}$ Reduction at Room Temperature. J. Electrochem. Soc. 2008, 155 (1), B42-B49.

(41) Hori, Y.; Ito, H.; Okano, K.; Nagasu, K.; Sato, S. Silver-Coated Ion Exchange Membrane Electrode Applied to Electrochemical Reduction of Carbon Dioxide. Electrochim. Acta 2003, 48, 26512657. 
(42) Lee, W.; Kim, Y. E.; Youn, M. H.; Jeong, S. K.; Park, K. T. Catholyte-Free Electrocatalytic $\mathrm{CO}_{2}$ Reduction to Formate. Angew. Chem., Int. Ed. 2018, 57, 6883-6887.

(43) Ma, C.; Hou, P.; Wang, X.; Wang, Z.; Li, W.; Kang, P. Carbon Nanotubes with Rich Pyridinic Nitrogen for Gas Phase $\mathrm{CO}_{2}$ Electroreduction. Appl. Catal., B 2019, 250, 347-354.

(44) Liu, Z.; Masel, R. I.; Chen, Q.; Kutz, R.; Yang, H.; Lewinski, K.; Kaplun, M.; Luopa, S.; Lutz, D. R. Electrochemical Generation of Syngas from Water and Carbon Dioxide at Industrially Important Rates. J. CO2 Util. 2016, 15, 50-56.

(45) Wang, G.; Pan, J.; Jiang, S. P.; Yang, H. Gas Phase Electrochemical Conversion of Humidified $\mathrm{CO}_{2}$ to $\mathrm{CO}$ and $\mathrm{H}_{2}$ on Proton-Exchange and Alkaline Anion-Exchange Membrane Fuel Cell Reactors. J. CO2 Util. 2018, 23, 152-158.

(46) Aeshala, L. M.; Rahman, S. U.; Verma, A. Effect of Solid Polymer Electrolyte on Electrochemical Reduction of $\mathrm{CO}_{2}$. Sep. Purif. Technol. 2012, 94, 131-137.

(47) Millet, P.; Ngameni, R.; Grigoriev, S. a.; Mbemba, N.; Brisset, F.; Ranjbari, A.; Etiévant, C. PEM Water Electrolyzers: From Electrocatalysis to Stack Development. Int. J. Hydrogen Energy 2010, $35,5043-5052$.

(48) Marx, N.; Boulon, L.; Gustin, F.; Hissel, D.; Agbossou, K. A Review of Multi-Stack and Modular Fuel Cell Systems: Interests, Application Areas and on-Going Research Activities. Int. J. Hydrogen Energy 2014, 39 (23), 12101-12111.

(49) Grosse, P.; Gao, D.; Scholten, F.; Sinev, I.; Mistry, H.; Roldan Cuenya, B. Dynamic Changes in the Structure, Chemical State and Catalytic Selectivity of $\mathrm{Cu}$ Nanocubes during $\mathrm{CO}_{2}$ Electroreduction: Size and Support Effects. Angew. Chem., Int. Ed. 2018, 57 (21), 61926197.

(50) Gao, H.; Wang, Y.; Xiao, F.; Ching, C. B.; Duan, H. Growth of Copper Nanocubes on Graphene Paper as Free-Standing Electrodes for Direct Hydrazine Fuel Cells. J. Phys. Chem. C 2012, 116 (14), $7719-7725$.

(51) Janáky, C.; Hursán, D.; Endrődi, B.; Chanmanee, W.; Roy, D.; Liu, D.; de Tacconi, N. R.; Dennis, B. H.; Rajeshwar, K. Electro- and Photoreduction of Carbon Dioxide: The Twain Shall Meet at Copper Oxide/Copper Interfaces. ACS Energy Lett. 2016, 1 (2), 332-338.

(52) Van Der Laan, G. P.; Beenackers, A. A. C. M. Kinetics and Selectivity of the Fischer-Tropsch Synthesis: A Literature Review. Catal. Rev.: Sci. Eng. 1999, 41 (3-4), 255-318.

(53) Weng, L.-C.; Bell, A. T.; Weber, A. Z. Towards MembraneElectrode Assembly Systems for $\mathrm{CO}_{2}$ Reduction: A Modeling Study. Energy Environ. Sci. 2019, 12 (6), 1950-1968.

(54) Yin, Z.; Peng, H.; Wei, X.; Zhou, H.; Gong, J.; Huai, M.; Xiao, L.; Wang, G.; Lu, J.; Zhuang, L. An Alkaline Polymer Electrolyte $\mathrm{CO}_{2}$ Electrolyzer Operated with Pure Water. Energy Environ. Sci. 2019, DOI: 10.1039/C9EE01204D. 